\title{
Article
}

\section{Exposure to the Fashion Industry: A Design Student Perspective}

\author{
Hunt, Carole and Brewer, Gayle
}

Available at http://clok.uclan.ac.uk/17836/

Hunt, Carole ORCID: 0000-0002-2702-6003 and Brewer, Gayle ORCID: 00000003-0690-4548 (2017) Exposure to the Fashion Industry: A Design Student Perspective. International Journal of Fashion Design, Technology and

Education . ISSN 1754-3266

It is advisable to refer to the publisher's version if you intend to cite from the work. http://dx.doi.org/10.1080/17543266.2017.1298159

For more information about UCLan's research in this area go to

http://www.uclan.ac.uk/researchgroups/ and search for < name of research Group>.

For information about Research generally at UCLan please go to http://www.uclan.ac.uk/research/

All outputs in CLoK are protected by Intellectual Property Rights law, including Copyright law. Copyright, IPR and Moral Rights for the works on this site are retained by the individual authors and/or other copyright owners. Terms and conditions for use of this material are defined in the policies page.

\section{CLoK}

Central Lancashire online Knowledge www.clok.uclan.ac.uk

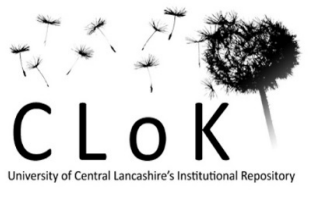




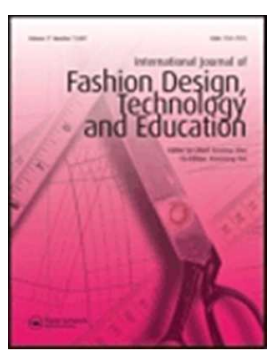

\section{Exposure to the Fashion Industry: A Design Student Perspective}

\begin{tabular}{|r|l|}
\hline Journal: & International Journal of Fashion Design, Technology and Education \\
\hline Manuscript ID & TFDT-2016-0058.R1 \\
\hline Manuscript Type: & Research Paper \\
\hline Keywords: & body dissatisfaction, design, fashion, industry, student \\
\hline \multicolumn{2}{|c}{} \\
\hline
\end{tabular}

SCHOLARONE ${ }^{m}$

Manuscripts 


\title{
Exposure to the Fashion Industry: A Design Student Perspective
}

\author{
It has been argued that the fashion industry represents a "toxic" environment which increases the \\ incidence of body dissatisfaction and eating disorders amongst both fashion models and \\ consumers (Treasure, Wack, \& Roberts, 2008). There is however a paucity of information \\ investigating the experiences of women that are not modelsdesigners working in the fashion \\ industry. The present study addresses this limitation and considers the experiences of female \\ fashion design students. Interviews were conducted with eight students and subjected to \\ interpretative phenomenological analysis. Three master themes emerged from the analysis. These \\ were: Personal Style; Body Dissatisfaction; and Design. Two sub-themes formed the Personal \\ Style theme: Casual and Comfortable and Covered and Protected. The Body Dissatisfaction \\ theme contained two sub-themes: Personal Experience and Industry Exposure. The Design theme \\ contained three sub-themes: Strength and Confidence; Differences between Personal Style and \\ Design; and Gender. Findings have important implications for the recruitment, retention, and \\ wellbeing of female fashion design students.
}

Keywords: body dissatisfaction; design; fashion; industry; student

\subsection{Introduction}

A substantial proportion of women report dissatisfaction with their appearance (McCabe \& Ricciardelli, 2001; Tiggemann, 2004) characterised by negative cognitions, emotions, and behaviours. Dissatisfaction is associated with a range of negative consequences including social anxiety, impaired sexual functioning, depression or suicidal ideation, and disordered eating (e.g., Brausch \& Gutierrez, 2009; Ziegler, et al. 2005). The prevalence of body dissatisfaction is 
expected to continue as the importance placed on physical appearance continues to rise (Cash, Morrow, Hrabosky, \& Perry, 2004) and people have become more accepting of extreme forms of body modification such as cosmetic surgery (Menzel, et al. 2011).

Though body dissatisfaction has been described as normative (Cash, 2004) a range of factors are associated with increased risk. In particular, media exposure is associated with body dissatisfaction, drive to thinness, and disordered eating (e.g., Fernandez \& Pritchard, 2012; Walker et al. 2015). Furthermore, women report dissatisfaction with the restricted range of body sizes depicted in the media and widespread objectification of women (Diedrichs, Lee, \& Kelly, 2011). The images portrayed by the fashion industry may be particularly problematic. For example, models appearing in fashion magazines are more likely to emphasise appearance compared to those in other contexts such as fitness magazines which may highlight achievement and performance (Wasylkiw, Emms, Meuse, \& Poirier, 2009). Furthermore, thin ideal internalization but not athletic ideal internalization influences body dissatisfaction and dieting behaviour (Homan, 2010).

Indeed, it has been argued that the fashion industry has created a "toxic" environment which increases the likelihood of body dissatisfaction and eating disorders (Treasure, Wack, \& Roberts, 2008). For example, fashion magazines appear to promote the thin ideal (Perez-Lugo, Gabino-Campos, \& Baile, 2016). Previous research indicates that the fashion industry influences both consumers of fashion based media and those working in the sector. Specifically, studies have shown that professional models report a higher drive for thinness, dysfunctional investment in appearance, eating disorder symptoms, and eating disorders (e.g., Swami \& Szmigielska, 2013). Weight concern amongst models may be exacerbated by the widespread employment of clinically underweight models (Preti, Usai, Miotto, Petretto, \& Masala, 2008). Despite the 
relationship between exposure to the fashion industry and body dissatisfaction amongst fashion consumers and models, there is a paucity of information investigating the experiences of other individuals (i.e., non-models) working in the fashion industry.

The present study addresses this limitation and considers the experiences of female fashion design students. Previous research has demonstrated that observing images of thin models is associated with increased body dissatisfaction and disordered eating (Grabe, Ward, \& Hyde, 2008) and exposure to fashion blogs is associated with higher thin ideal internalization (Lunde, 2013). Therefore, we expect exposure to this form of objectification to also impact on the manner in which designers perceive themselves. It is also predicted that these experiences will influence the manner in which women engage in the design process.

\subsection{Method}

\subsection{Participants}

Participants $(N=8)$ were final year undergraduate fashion design students attending a British University. Participant age ranged from 23 to 27 years and all were female. All participants had spent a year on placement gaining industrial experience in a fashion related subject. At the time of the study, Pparticipants were working toward their final end of year, BA Hons in Fashion Design, Graduate Collection and all participants had chosen to focus on women's wear. These women constitute a purposive sample and were recruited via announcements to the student cohort.

\subsection{Materials and Procedure}

Prior to interview, participants completed a questionnaire identifying age, length of time studying design, length of time working in the design industry, and relevant prior experience. 
Individual semi-structured interviews were then conducted at the host institution, with only the interviewer and interviewee present. Open-ended questions prompted participants to narrate and reflect on their experiences. The interview schedule was prepared following appropriate guidelines (Smith, 1995) and questions were framed to obtain information about a range of subjects. Interviews were recorded on a portable hand-held device and transcribed verbatim. Interviews were anonymised at the point of transcription and subject to interpretive pPhenomenological âAnalysis (Smith, 1996).

Interpretative $\mathrm{p} P$ henomenological aAnalysis provides a position and protocol for the analysis of experiential qualitative data (Smith \& Osborn, 2003). The method adopts phenomenological, hermeneutic, and idiographic perspectives (Smith, Flowers, \& Larkin, 2009) andwhich seeks to describe, interpret, and understand the lived experience of a population and the manner in which individuals make sense of this lived experience. The researcher listened to the recordings and read the interview transcripts several times to aid familiarisation. Notes were made of significant areas of the text to highlight items that were potentially interesting or significant. Following further readings of the transcripts, notes were formed into emergent themes. The researcher then identified relationships between emerging themes and these were grouped into superordinate themes and sub-themes. The process was validated by discussions between the first and second author, during which the appropriateness of each theme and subtheme was established. Appropriate Pprinciples (e.g. Braun \& Clarke, 2013; proposed by $\underline{\text { Smith, }}$ Flowers, \& Larkin, 2009Smith, et al. (2009; Smith \& Osborn, 2003)) were adhered to throughout the data collection and analytic process to provide rigor and cohesion.

\subsection{Results}


Interpretative phenomenological analysis of interview transcripts generated three superordinate themes: (1) Personal Style; (2) Body Dissatisfaction; and (3) Design. Each Superordinate theme contained a number of sub-themes, as detailed in Table 1.

[Table 1 near here]

\subsection{Personal Style}

\subsubsection{Casual and Comfortable}

Each participant commented on their preference for casual clothes and prioritized comfort and convenience rather than style or expression. For example, 'I want to be comfortable' (Participant 5). In particular, women mentioned 'loose', 'baggy', and 'oversized' clothing and often wore jeans and sweaters. For two students the preference for casual clothing was functional and reflected the extent to which they moved around during the design process. For example, 'I think it's too restricting like it's hard to sit and do any work if you've got like a tight top on or a tight skirt' (Participant 2) and 'It's usually more oversized kind of clothes, loose fitting to kind of move around' (Participant 4).

\subsubsection{Covered and Protected}

Four participants specifically commented that they selected clothes which covered their figures. For example, 'I was self-conscious about myself, wanted to be covered and wrapped up in layers and things' (Participant 4). They described wanting to feel 'more protected'. For example, Participant 1 stated 'I normally wear baggy stuff and like I just like I feel a bit like more protected'. Clothes were often selected in order to conceal specific areas of the body such as the stomach or upper arms. As described by Participant 5, 'Like I don't like the top of my arms or my stomach so if I wear loose clothing it'll just hide it all and even a loose t-shirt 
because I'm like protecting over my stomach and like and hide it all day'. The tendency to select this type of clothing varied across time and women suggested that factors such as mood influenced clothing choice. For example, 'If I'm in an okay mood just a normal kind of happy medium, I'll tend to wear maybe a short sleeve t-shirt and then some days when I'm not feeling as good as the others I'll put on a long sleeve t-shirt on and cover up yeah which I've been told that it comes through in my design work' (Participant 4) and 'If I feel bloated or funny I might put on a baggy jumper' (Participant 8 ).

\subsection{Body Dissatisfaction}

\subsubsection{Personal Experience}

Each participant commented on their own body dissatisfaction issues and / or disordered eating. For example, 'Yeah cos I erm, like I've had depression to do with eating and stuff from first, second year' (Participant 1). For some students this preceded the course whereas for others this occurred whilst at university. For example, 'A lot of my issues happened to me before I was like in the design industry and that was more pure based on social media, celebrities magazines and one of my friends she was a model as well' (Participant 5). Similarly, 'From a long time I was very self-conscious, when I was in my teens I mean went to an all-girls school that didn't set me up in the right mind frame and then being exposed by skinny models and beautiful pictures I think it doesn't help I was already very self-conscious growing up so it made you think oh my God and question everything. I've seen a lot of people where it impacted them a lot to the point of illness because they are surrounded by pretty and skinny girls and boys' (Participant 8). Some women reported that these experiences influenced their work, 'I haven't been that confident with my body which I think is why my shapes have been bigger so they're on my body and a lot more covering the model' (Participant 7). Some students stated that they intended to use these 
experiences in a positive way; especially using their issues to raise awareness or inspire design. For example 'I wanted to portray it through creative things, make something productive from it, and not always be like a negative thing' (Participant 1) and 'It can be really difficult but in the last few years I've really used my work to make me feel better, be inclusive with the way I design and celebrate body shapes' (Participant 8).

\subsubsection{Industry Exposure}

Six participants commented on the negative impact of the design industry on their body dissatisfaction. For example, 'I remember something just clicked in second year I was doing my work and I was just feeling bad about myself from looking on imagery and I knew I had put on a bit of weight and I don't know something must have clicked I don't know...I remember doing a project after coming back from first year and looking at models and thought why don't I look like that and why do they look like that' (Participant 1). One student described a particularly negative experience which occurred whilst on placement within industry. 'While I was on placement at [company], I was a fit model for a year...It wasn't in my job description, I thought I was helping out at first coz they were short and didn't have anybody and I'd have to get changed in front of all my bosses, all my colleagues kind of thing. And at first it was kinda really un nerving for me, I didn't enjoy it, I just did it to kind of please them...I remember one time, we had this sample coming in from China and it was absolutely tiny and they were like oh can you put this one, so I did. The trousers wouldn't go pass my thighs and I must have stood in front of about ten people trying to squeeze these trousers on and they were all looking at me really annoyed that I didn't fit into them, even though I'm not technically to be a fit model, I was there to design and I was a designers assistant' (Participant 4). However, industry exposure could also be a positive experience which broadened the perceived scope of the fashion industry 'I think 
being able to have gone for a year and doing placement has given me more confidence because the models are one aspect of what you see in the designer industry' (Participant 7).

\subsection{Design}

\subsubsection{Strength and Confidence}

Each participant reported that they wished for their clients to be strong confident women. For example, 'Definitely confident, erm, feel like she has power, feel like she can conquer the world and feel like definitely stand out from the crowd and everything and yeah just be herself' (Participant 3), and 'The woman I'm designing for I want her to feel confident and strong but still have her femininity about her as well' (Participant 6). Women also indicated that this confidence would encourage those wearing their clothes to feel powerful and motivated to achieve 'Like she can take on the world if she wears this dress or this suit what not... she can get her day done and crack on with it not have to worry about the way she looks cos she knows she looks really good' (Participant 4). Hence 'They are going to be someone who is out there not worried about other people think someone who is wanting to make an impact and they're willing to stand out' (Participant 7).

\subsubsection{Differences between Personal Style and Design}

Five participants explicitly discussed differences between their own clothes and the garments they design. For example, 'I would never wear them but that is the silhouette I follow... I've always done it fitted but I've never modelled it myself and I think a lot of people model their own work and I just wouldn't do that ever' (Participant 2) and 'When I dress I dress in very bring dull, black but when I'm designing it's something completely the opposite it's incredibly colourful' (Participant 8). Designers typically selected their own clothes for practical 


\begin{abstract}
reasons and chose to express themselves through their work. Women were often more adventurous when designing. For example, 'It's just not something I would ever wear, so maybe it's a bit of escapism in other clothes' (Participant 2), 'I think when I'm designing I tend to go for a more adventurous fabrics' (Participant 4). In part, differences between the clothes worn and designed by the students reflected their own self-consciousness and the desire to create garments for confidence women. As summarized by one student 'What I'm designing I'm sure there are lot of people who won't be confident enough to wear them but it is its doing the opposite of me and creating the opposite of me' (Participant 7).
\end{abstract}

\title{
3.3.3 Gender
}

Five participants commented on sex differences in the design process or in experiences of the fashion industry per se. Women typically reported that men place a greater emphasis than women on sexuality. For example, 'Maybe they see the body different to what a woman would see it you know' (Participant 1), 'Men, I feel like they'll probably be like more sexier than women. I don't think women think about being sexier but really making a statement, I think it depends on, from my own point the men want to make the woman feel more sexier' (Participant 3), and 'Women go for whether the woman feels comfortable and happy. Whereas, men designer might go more for making them look sexier' (Participant 7). Women were also conscious of sexism within the fashion industry which contributed to the success of male designers. For example, 'I guess with big designers, the women do all the back work but he's the face of it...There's one boy in our whole class and more than likely he's the one who gets the job... in general he's more likely to get a job than the other 30 women in the class' (Participant 2).

\subsection{Discussion}


Findings suggest that female fashion design students experience negative body dissatisfaction and for some women this is directly related to exposure to the fashion industry. These findings are consistent with our first hypothesis. Though women commented on specific aspects of fashion design (such as the use of slender models), additional research is required to determine those aspects of the industry which are most influential. For example, the overall emphasis on appearance may encourage self-objectification (i.e., internalization of the observer's perspective of the physical self, leading to the individual viewing themselves in objectified terms). The self-objectification can lead to repeated monitoring of physical appearance, body dissatisfaction, and disordered eating. The selection of loose or oversized clothing may therefore be used to reduce objectification either by others or the self (Fredrickson \& Roberts, 1997).

Furthermore, women appeared to avoid wearing particular clothing and wished to remain 'covered and protected'. This is consistent with previous research indicating that body dissatisfaction is related to a range of clothing oriented appearance management behaviours such as avoidance of brightly coloured, revealing, or tightly fitting clothing in order to use clothing as a form of camouflage (Trautmann, Worthy, \& Lokken, 2007). Hence, women approached their own clothing and their designs differently. For their own clothing women selected comfortable clothing which covered their bodies and chose to express themselves through more adventurous designs which (though they would not wear these themselves) they wished would be worn by strong confident women. Therefore, the fashion environment appeared to influence the manner in which students perceived themselves and their own clothing preferences rather than the design process per se (our second hypothesis).

These preliminary findings indicate that female fashion design students may be at increased risk of body dissatisfaction or other negative consequences. 
The incidence of body dissatisfaction and disordered eating reported and the manner in which these relate to participation in the course or placement issues raised by the present study are of concern to educators supporting design students. Though formal support is available (e.g. counselling services) additional interventions may be beneficial. Interventions have successfully increased satisfaction with personal appearance (Alleva, Martijn, Van Breukelen, Jansen, \& Karos, 2015) and may be used to enhance body appreciation rather than targeting those experiencing body dissatisfaction only. Previous research indicates that body appreciation protects women from media-induced body dissatisfaction (Andrew, Tiggemann, \& Clark, 2015) and may therefore also protect women from dissatisfaction associated with exposure to the appearance oriented fashion industry. The use of more realistically sized mannequins and models may also be advisable as observing average sized models is associated with a positive body image (Halliwell, Dittmar, \& Howe, 2005). Interventions should of course be carefully monitored as for example disclaimers introduced to address body image concerns may actually direct attention towards specific body areas and increase body dissatisfaction (Bury, Tiggemann, \& Slater, 2016). Educators and employers supporting students during work placements should be aware of these issues in order to support or refer students for support as appropriate.

Furthermore, as students are likely to enter the fashion industry, future research should investigate the extent to which appearance orientation and body dissatisfaction impact on employee wellbeing.

Consistent with previous research (e.g. Sternheim, Konstantellou, Startup, \& Schmidt, 2011; Thompson \& Broom, 2009) and recommendations for interpretative phenomenological analysis (Braun \& Clarke, 2013; Smith, Flowers, \& Larkin, 2009), the present study recruited a small relatively homogenous sample. In particular, Fthe present study recruited women from a 
British University, $\mathrm{h}$.Hence, participants were predominantly British and Caucasian.-_Important cross-cultural differences may occur in relation to both fashion involvement and appearance concerns. For example, previous research has identified important variation with regard to fashion leadership (i.e., adoption of fashion related items and contribution to the dissemination of a style or trend) and body display avoidance (Maphis, Martz, Bergman, Cutin, \& Webb, 2013; Shephard, Kinley, \& Josiam, 2014). Furthermore, the ethnicity, culture, clothing, and body dissatisfaction may interact. For example, Muslim women wearing traditional dress report a lower drive for thinness and pressure to obtain a thin ideal standard of beauty than those wearing Western dress (Dunkel, Davidson, \& Qurashi, 2010). Hence, additional cross-cultural research is required to determine those factors which strengthen or weaken the relationship between fashion industry exposure and body dissatisfaction.

Similarly, the current study focused on women's experiences only. A substantial proportion of men report body dissatisfaction (Jung, Forbes, \& Chan, 2010) and those observing slender male models report lower self-rated attractiveness (Ogden \& Mundray, 1996), suggesting similar experiences may occur for male fashion students. However, fashion involvement (i.e., "the extent to which a consumer views the related fashion [clothing] activities as a central part of their life" O'Cass, 2004, p870) is higher amongst women than men (Hourigan \& Bougour, 2012), and women are more likely than men to avoid clothes which make them aware of their body shape (Reas, Grilo, Masheb, \& Wilson, 2005) suggesting that important differences between men and women may occur. Therefore, future research should consider the experiences of male designers. Researchers may also investigate the experiences of other (i.e. non-designer) $\underline{\text { students and professionalss }}$ working in the fashion industry. For example, those engaged in 
fashion promotion, management, or fashion journalism also work in an environment focusing on appearance and may engage in unrealistic comparisons leading to greater body dissatisfaction.

To conclude, interviews were conducted with eight fashion design students and subjected to interpretative phenomenological analysis. Three superordinate themes emerged from the analysis. These were: Personal Style; Body Dissatisfaction; and Design. Two sub-themes formed the Personal Style theme: Casual and Comfortable and Covered and Protected. The Body Dissatisfaction theme contained two sub-themes: Personal Experience and Industry Exposure. The Design theme contained three sub-themes: Strength and Confidence; Differences between Personal Style and Design; and Gender. Overall, Ffindings suggest that the potentially "toxic" fashion environment which impacts on models and consumers, also impacts on design student body dissatisfaction and eating behaviour. As a consequence, these women selected clothes to cover and 'protect' their bodies. The environment did not negatively influence the design process however and students created garments intended for 'strong, confident' women. These findings have important implications for the recruitment, retention, and wellbeing of female fashion design students and future research focusing on the development and evaluation of appropriate interventions is recommended.-

\subsection{References}

Alleva, J.M., Martjin, C., Van Breukelen, G.J.P., Jansen, A., \& Karos, K. (2015). Expand Your Horizon: A programme that improves body image and reduces self-objectification by training women to focus on body functionality. Body Image, 15, 81-89.

Andrew, R., Tiggemann, M., \& Clark, L. (2015). The protective role of body appreciation against media-induced body dissatisfaction. Body Image, 15, 98-104. 

London: Sage.

Brausch, A.M., \& Gutierrez, P.M. (2009). The role of body image and disordered eating as risk factors for depression and suicidal ideation in adolescents. Suicide and Life Threatening Behavior, 9, 58-71.

Bury, B., Tiggemann, M., \& Slater, A. (2016). Disclaimer labels on fashion magazine advertisements: Impact on visual attention and relationship with body dissatisfaction. Body Image, 16, 1-9.

Cash, T.F. (2004). Body image: Past, present, and future. Body Image, 1, 1-5.

Cash, T.F., Morrow, J.A., Hrabosky, J.I., \& Perry, A.A. (2004). How has body image changed? A cross-sectional investigation of college women and men from 1983 to 2001 . Journal of Consulting and Clinical Psychology, 72, 1081-1089.

Diedrichs, P.C., Lee, C., \& Kelly, M. (2011). Seeing the beauty in everyday people: A qualitative study of young Australians' opinions on body image, the mass media and models. Body Image, 8, 259-266.

Dunkel, T.M., Davidson, D., \& Qurashi, S. (2010). Body satisfaction and pressure to be thin in younger and older Muslim and non-Muslim women: The role of Western and nonWestern dress preferences. Body Image, 7, 56-65.

Fernandez, S., \& Pritchard, M. (2012). Relationships between self-esteem, media influence and drive for thinness. Eating Behaviors, 13, 321-325. 
Fredrickson, B.L., \& Roberts, T.A. (1997). Objectification theory: Toward understanding women's lived experiences and mental health risks. Psychology of Women Quarterly, 21, 173-206.

Grabe, S., Ward, L.M., \& Hyde, J.S. (2008). The role of the media in body image concerns among women: A meta-analysis of experimental and correlational studies. Psychological Bulletin, 134, 460-476.

Halliwell, E., Dittmar, H., \& Howe, J. (2005). Short research note: The impact of advertisements featuring ultra-thin or average-size models on women with a history of eating disorders. Journal of Community \& Applied Social Psychology, 15, 405-413.

Homan, K. (2010). Athletic-ideal and thin-ideal internalization as prospective predictors of body dissatisfaction, dieting, and compulsive exercise. Body Image, 7, 240-245.

Hourigan, S.R., \& Bougoure, U.S. (2012). Towards a better understanding of fashion clothing involvement. Australasian Marketing Journal, 20, 127-135.

Jung, J., Forbes, G.B., \& Chan, P. (2010). Global body and muscle satisfaction among college men in the United States and Hong Kong China. Sex Roles, 63, 104-117.

Lunde, C. (2013). Acceptance of cosmetic surgery, body appreciation, body ideal internalization, and fashion blog reading among late adolescents in Sweden. Body Image, 10, 632-635.

Maphis, L.E., Martz, D.M., Bergman, S.S., Curtin, L.A., \& Webb, R.M. (2013). Body size dissatisfaction and avoidance behavior: How gender, age, ethnicity, and relative clothing size predict what some won't try. Body Image, 10, 361-368.

McCabe, M.P., \& Ricciardelli, L.A. (2001). Body image and body change techniques among young adolescent boys. Eating Disorders Review, 9, 335-347. 
Menzel, J.E., Sperry, S.L., Small, B., Thompson, J.K., Sarwer, D.B., \& Cash, T.F. (2011). Internalization of appearance ideals and cosmetic surgery attitudes: A test of the tripartite influence model of body image. Sex Roles, 65, 469-477.

O'Cass, A. (2004). Fashion clothing consumption: Antecedents and consequences of fashion clothing involvement. European Journal of Marketing, 38, 869-882.

Ogden, J., \& Mundray, K. (1996). The effect of the media on body satisfaction: The role of gender and size. European Eating Disorders Review, 4, 171-182.

Perez-Lugo, A.L., Gabino-Campos, M., \& Baile, J.I. (2016). Analysis of the aesthetic stereotypes of women in nine fashion and beauty Mexican magazines. Revista Mexicana de Trastornos Alimentarios, 7, 40-45.

Preti, A., Usai, A., Miotto, P., Petretto, D.R., \& Masala, C. (2008). Eating disorders among professional fashion models. Psychiatry Research, 159, 86-94.

Reas, D.L., Grilo, C.M., Masheb, R.M., \& Wilson, G.T. (2005). Body checking and avoidance in overweight patients with binge eating disorder. International Journal of Eating Disorders, 37, 342-346.

Santonastaso, P., Ferrara, S., Sala, A., Vidotto, G., Delle Grave, R., Probst, M., \& Favaro, A. (1995). Confronto degli atteggiamenti corporei di un gruppo di pazienti con disturb dello'alimentazione con un campione di studentesse: Validazione italiana del Body Attitudes Test (BAT). Rivista Sperimentale di Freniatria CXIX, 423-436.

Shephard, A.J., Kinley, T.R., \& Josiam, B.M. Fashion leadership, shopping enjoyment, and gender: Hispanic versus Caucasian consumers’ shopping preferences. Journal of Retailing and Consumer Services, 21, 277-283. 
Smith, J.A. (1995). Semi-structured interviewing and qualitative analysis. In J.A. Smith, R.

Harre, \& L. van Langenhove (Eds.). Rethinking methods in psychology. London: Sage.

Smith, J.A. (1996). Beyond the divide between cognition and discourse: Using Interpretative

Phenomenological Analysis in health psychology. Psychology and Health, 11, 261-271.

Smith, J.A., Flowers, P., \& Larkin, M. (2009). Interpretive phenomenological analysis: Theory, method and research. London: Sage.

Smith, J.A., \& Osborn, M. (2003). Interpretative phenomenological analysis. In J.A. Smith (ed.). Qualitative psychology: A practical guide to methods (pp. 51-80). London: Sage.

Sternheim, L., Konstantellou, A., Startup, H., \& Schmidt, U. (2011). What does uncertainty $\underline{\text { mean to women with anorexia nervosa? An interpretative phenomenological analysis. }}$ Eating Disorders Review, 19, 12-24.

Formatted: Font: Times New Roman, 12 pt, Italic, English (U.K.)

Swami, V., \& Szmigielska, E. (2013). Body image concerns in professional fashion models: Are they really an at-risk group? Psychiatry Research, 207, 113-117.

Thompson, A.R., \& Broom, L. (2009). Positively managing intrusive reactions to disfigurement: An interpretative phenomenological analysis of naturalistic coping. Diversity \& Equality in Health Care, 171-180.

Tiggemann, M. (2004). Body image across the adult life span: Stability and change. Body Image, $1,29-41$.

Trautmann, J., Worthy, S.L., \& Lokken, K.L. (2007). Body dissatisfaction, bulimic symptoms, and clothing practices among college women. The Journal of Psychology, 141, 485-498. 
Treasure, J.L., Wack, E.R., \& Roberts, M.R. (2008). Models as a high risk group: The health implications of a size zero culture. British Journal of Psychiatry, 192, 243-244.

Walker, M., Thornton, L., De Choudhury, M., Teevan, J., Bulik, C.M., Levinson, C.A., \& Zerwas, S. (2015). Facebook use and disordered eating in college-aged women. Journal of Adolescent Health, 57, 157-163.

Wasylkiw, L., Emms, A.A., Meuse, R., \& Poirier, K.F. (2009). Are all models created equal? A content analysis of women in advertisements of fitness versus fashion magazines. Body Image, 6, 137-140.

Ziegler, P.J., Kannan, S., Jonnalagadda, S.S., Krishnakumar, A., Taksali, S.E., \& Nelson, J.A. (2005). Dietary intake, body image perceptions, and weight concerns of female US International Synchronized Figure Skating Teams. International Journal of Sport Nutrition and Exercise Metabolism, 15, 550-566. 
Table 1: Superordinate and Sub-Themes

\begin{tabular}{ll}
\hline Superordinate Theme & Sub-Theme \\
\hline Personal Style & Casual and Comfortable \\
& Covered and Protected \\
Body Dissatisfaction & Personal Experience \\
& Industry Exposure \\
Design & Strength and Confidence \\
& Differences between Personal Style and Design \\
& Gender \\
\hline
\end{tabular}

